\title{
Chagas Disease Vector Control in Tupiza, Southern Bolivia
}

\section{G Guillen*, R Diaz, A Jemio*,」 Alfred Cassab**, C Teixeira Pinto***, C) Schofield $* * * * /+$}

Proyecto de Desarrollo Agropecuario Cotagaita San Juan del Oro, Componente Salud, Calle Suipacha, Tupiza, Bolivia * Secretaria Nacional de Salud, Dirección Nacionall de Vigilancial y Control de Enfermedades y Riesgos, Capitan Ravelo 2 199, La Paz, Bolivia **Asociación Fundaciónl Pro-Vida y Salud (PROVISA), Casilla 14112, La Paz, Bolivia ***Hoechst Schering AgrEvo do Brasil, Av. das Nações Unidas 18001, 04795900 Sãol Paulo, SP, Brasill ****Department of Medical Parasitology, London School of Hygiene and Tropical Medicine, London WCI E7HT, UK

Heavy domestic andperidomestic infestations of Triatoma infestans were controlled in two villages in southern Bolivia by the application of deltamethrin SC25 (2.5\% suspension concentrate) at a target dose of $25 \mathrm{mg}$ a.i. $/ \mathrm{m}^{2}$. Actual applied dose was monitored by HPLC analysis of filter papers placed at various heights on the house walls, and was shown to rangefrom 0 to 59.6 about a mean of $28.5 \mathrm{mg}$ a. i./ $m$ ? Wall bioassays showed high mortality of $\mathrm{T}$. infestans during the first month after the application of deltamethrin. Mortality declined to zero as summer temperatures increased, but reappeared with the onset of the following winter. In contrast, knockdown was apparent throughout the trial, showing no discernible temperature dependence.

House infestation rates, measured by manual sampling and use of paper sheets to collect bugfaeces, declined from $79 \%$ at the beginning of the trial to zero at the 6 month evaluation. All but one of the houses were stillfree of $\mathrm{T}$. infestans at the final evaluation 12 months after spraying, although a small number of bugs werefound at this time in 5 of 355peridomestic dependencies. Comparative cost studies endorse the recommendation of large-scale application of deltamethrin, or pyrethroid of similar cost- $\mid$ effectiveness, as a means to eliminate domestic T. infestans populations in order to interrupt transmission of Chagas disease.

Key words: Triatoma infestans - Chagas disease - vector control - pyrethroids - Bolivia

Bolivia has amongst the highest indices of Chagas disease in the Americas. Between 1.1 and 1.8 million people are believed to be infected with the causative agent, Typanosoma cruzi, which represents over $15 \%$ of the 1990 population $(\mathrm{PAHO}$ 1984, Valencia 1990, WHO 1992). The endemic area comprises around $55 \%$ of national territory (about $600,000 \mathrm{~km}^{2}$ ) where about 3.5 million people are considered at risk to the infection (SNS 1994). In highly endemic communities, especially in the Departments of Cochabamba, Chuquisaca, Tarija, Santa Cruz and Potosi, seroprevalence rates may reach close to $100 \%$ in older age groups. The annual cost of the disease to the Bolivian economy, summing costs of symptomatic treatment for acute and chronic cases together with estimates of productive years lost, has been estimated at just over US\$120 million (SNS/CCH 1994).

'Corresponding author. 7 rue Maclonay, Pregnin, St. Genis-Pouilly, 01630 France. Tel/Fax: +33-4-50.206377 Received 1 April 1996

Accepted 2\| October 1996
Throughout Bolivia, vectorial transmission of T] cruzi is almost exclusively due to domestic populations of Triatoma infestans, and the distribution of this species closely matches that of the human disease (Fig. 1). In the absence of satisfactory therapy or vaccines against Chagas disease, control relies primarily on interrupting transmission by eliminating domestic populations of T] infestans. This generally involves insecticide spraying of domestic and peridomestic habitats, with or without attempts tol improve the physical structure of habitats in order to eliminate cracks and crevices where the vectors may hide. However, although vector control has been carried out extensively in other countries of Latin America since the 1950s, control activities in Bolivia were virtually non-existent until the mid-1980s. Since 1982, several NGOs and research organizations have been operating projects incorporating aspects of Chagas disease vector control (Table I). This paper reports on one such trial carried out in two villages in southem Bolivia, near the town of Tupiza, under the auspices of the "Proyecto de Desarrollo Agropecuario Cotagaita San Juan dellOro"] 


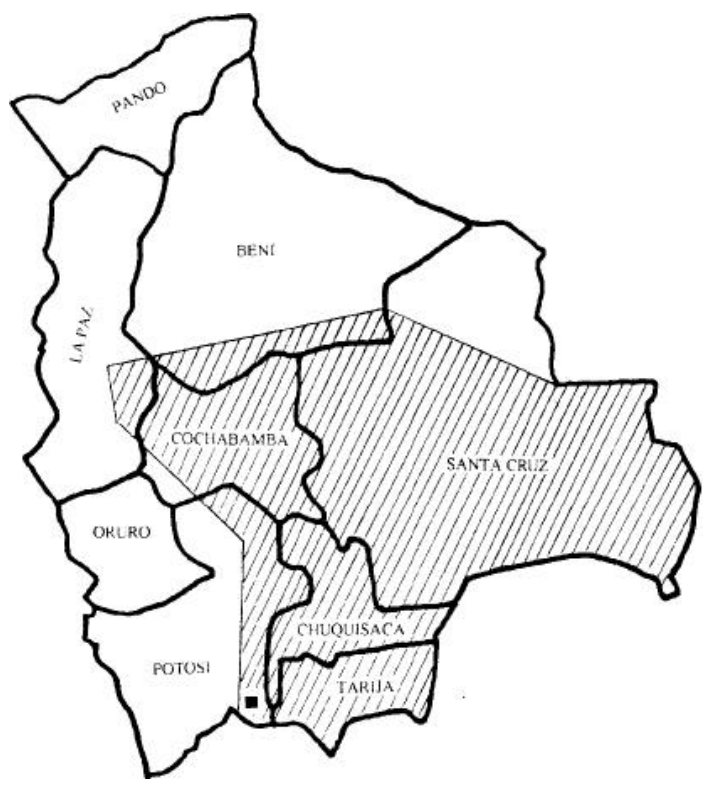

Fig. I map of Bolivia showing approximate Departmental boundaries and estimated distribution of Triatoma infestans (shaded). Project area in southern Bolivia is indicated by solid square.

\section{TABLE I}

Activities against Chagas disease vectors in Bolivia, up to March $1995^{a}$

\begin{tabular}{lccc}
\hline & $\begin{array}{c}\text { Houses } \\
\text { sprayed } \\
\text { only }\end{array}$ & $\begin{array}{c}\text { Houses } \\
\text { sprayed and } \\
\text { improved }\end{array}$ & Total \\
\cline { 2 - 4 } Cochabamba & 4524 & 3924 & 8448 \\
Chuquisaca & - & 4623 & 4623 \\
La Paz & 301 & $26039 b$ & $28770 b$ \\
Potosi & 2731 & 1604 & 2357 \\
Santa Cruz & 753 & 103 & 103 \\
Tarija & & & \\
\hline
\end{tabular}

a: source - Bolivian presentation to 4th Meeting of the Intergovernment Commission for the Elimination of Triatoma infestans, Asuncion, March 1995.

$b$ : includes 23,649 houses treated by the Proyecto Cotagaita San Juan dell Oro.

\section{MATERIALS AND METHODS}

Background and trialprotocol - The Projecto de Desarrollo Agropecuario Cotagaita San Juan del Oro (here abbreviated to P Cotagaita) was set up in 1982 through a cooperative agreement involving several different agencies (including FIDA, OPEC, CAF, and the Government of the Netherlands) (P Cotagaita 1994). It was primarily designed to improve the agricultural basis of the three southernmost provinces of the Department of Potosi: Nor Chichasl (capital $=$ Cotagaita), Sud Chichas (capital $=$ Tupiza), and Modesto Omiste (capital $=$ Villazon). Since 1986 however, the project has included a component of Chagas disease vector control based partly on insecticide spraying and partly on house improvement. To date, 23,649 houses have been sprayed and/orl improved as part of these activities, and community organizations have been set up to maintain vigilance and report any reinfestation by $T]$ infestans.

Although deltamethrin SC25 has been the primary insecticide used by the $\mathrm{P}$ Cotagaita against Chagas disease vectors, the project provided opportunity for a detailed trial and evaluation of this formulation against T] infestans. The trial protocol was submitted to and approved by the WHO Pesticide Evaluation Scheme (WHOPES) in February 1994, and was also approved by the Bolivian Secretaria Nacionall de Salud (SNS) and the P Cotagaita authorities for initiation in June 1994. The trial protocol specified complete indoor and outdoor spraying of all dwellings and peridomestic habitats in the trial communities, using deltamethrin SC25 (2.5\% suspension concentrate) at a target dose of $25 \mathrm{mg}$ a.i. $\left./ \mathrm{m}^{2}\right\rfloor$ Filter papers were to be fixed to the walls of a sample of houses for subsequent analysis of spray deposit, in order to check for quantity of insecticide applied.

Evaluation was to include prespray investigation of all houses for evidence of infestation with T] infestans, followed by similar postspray investigations at $1,3,6,9$ and 12 months. Houses were also to be monitored by providing householders with plastic bags in which to keep any bugs they found, and application of paper sheets on house walls to monitor evidence of bug faecall deposits (Garcia Zapata et al. 1985, Schofield et al. 1986) although in the event, paper sheets were applied only to 11 houses. Insecticide deposits were also to be monitored by wall surface bioassays in 10 houses using laboratory reared fifth instars of $T$ ] infestans.

Trial site - The trial was carried out in the two neighbouring communities of San Jose de la Pampa Grande and Entre Rios de Ajnapa. These communities are $3 \mathrm{~km}$ apart and lie about $36 \mathrm{~km}$ from the city of Tupiza. Although surrounding villages had been sprayed by the P Cotagaita team during 198990, these two communities had not been sprayed because of severe flooding during that period. Previous serological studies on 158 people from these two communities (using indirect haemaglutination and indirect immunofluorescence) had shown a mean seroprevalence for $T$ ] cruzi of $63 \%$ (Fig. 2) with ECG studies revealing one or more abnormalities in $90 \%$ of 58 seropositives, including 12 people with complete right bundle branch block.

The trial site is about $2,900 \mathrm{~m}$ above sea level, and is an extremely arid region dominated by xe- 


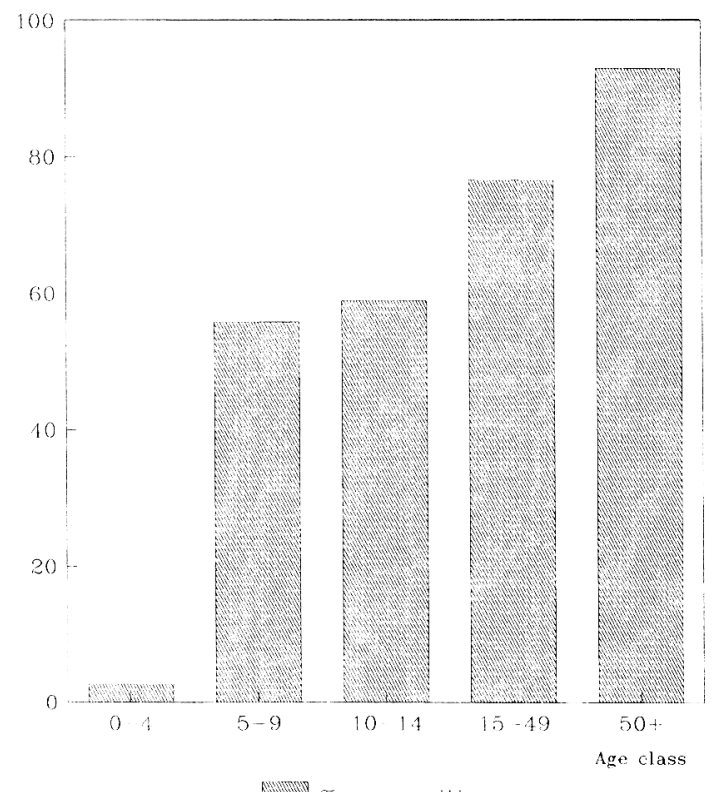

M $\%$ seropositive

Fig. 2: age related seroprevalence (by IHA and IIF) for infection with Trypanosoma cruzi in 158 people from the communities of San Jose de la Pampa Grande and Entre Rios de Ajnapa.

rophytic vegetation. Mean annual rainfall ranges from $200-1500 \mathrm{~mm}$, generally concentrated in the summer months (Dec.-Mar.). Monthly mean temperatures range from 11 to $20^{\circ} \mathrm{C}$. Summer temperatures may exceed $30^{\circ} \mathrm{C}$ but nighttime winter temperatures occasionally fall to below zero. Agriculture, mainly for maize and other cereals, relies on irrigation from the nearby river San Juan del Oro. There are few cattle, but sheep and goats are common. Wild guinea-pigs are much in evidence, nesting amongst rockpiles or under cactus stands on the rocky slopes around the houses.

Almost all houses in the two villages were constructed of adobe blocks, of which about $60 \%$ were faced with a plaster of seived earth and lime or cement. Roofs were generally of split cane covered with earth, or, less frequently, of ceramic tiles or corrugated fibre cement or metal sheets. Some houses were extremely old, said to be $50-100$ years or more (this was evidenced by the finding of parts of a 1934 English newspaper used to cover the inner door of one house). Older houses generally had an internal ceiling made of split canes covered with lime-based plaster. Most houses had an extensive peridomestic area involving goat corral, chicken coops and enclosures for donkeys and other livestock. These were usually contiguous with the houses, and constructed in a similar way with adobe blocks. Walls of corrals were invariably topped with cut branches of thorn scrub.
At the beginning of the trial there were 150 houses in San Jose, and 91 in Entre Rios. However, a feature of the two communities is that because of economic difficulties, the local villagers often migrate in search of work. Sometimes these migrations are seasonal - generally to other agricultural regions or cities in Bolivia - in which case the villagers return to their houses from time to time. But in some cases the migrations are further afield - to Argentina, for example - so that houses may be left unoccupied for several years. For this reason, the number of houses that could be checked during each periodic inspection was quite variable. In San Jose for example, only 79 houses were fully occupied at the beginning of the trial, with one other house used periodically by a family living nearby. In Entre Rios, only 44 houses were fully occupied.

Implementation of the trial - In San Jose, a total of 150 houses was sprayed during the period 15-19 June 1994, and the 91 houses in Entre Rios were sprayed during the same period. The spraying was carried out by 5 two-man teams using 81 Hudson X-pert backpacks. In most cases the spraying covered all internal and external walls of each house, together with peridomestic dependencies that comprised a total, in the two communities, of 68 chicken coops, 286 goat corrals, and 1 guineapiggery. Because of long-term absence of householders however, 12 houses in San Jose and 6 in Entre Rios could be sprayed only on the outside walls and peridomestic dependencies.

The target application dose was $25 \mathrm{mg}$ a.i. $/ \mathrm{m}^{2}$ on all sprayed surfaces. This was monitored during spraying by the on-site supervisor (CTP) in accordance with number of tank charges in relation to estimated surface area of each house and its peridomestic dependencies. In addition, four filter papers were pinned at various heights to walls of each of five houses selected at random. After spraying, these papers were sealed into individual plastic bags for subsequent HPLC analysis at the laboratories of Roussel-Uclaf (now Agrevo), Berkhamsted, UK. A total of 941 of insecticide (deltamethrin 2.5\% SC) was expended in San Jose (approx. 0.631 /house) and 52.81 in Entre Rios (approx. $0.581 /$ house). Spraymen reported no difficulties either in preparation of the product or in its application.

Evaluation - Prespray evaluation was carried out in 63 houses in San Jose, and 41 houses in Entre Rios. Houses were again examined at 1, 3, 6, 9 and 12 months postspray. In each case the procedure was similar: one person examined the inside of the house, the other examined the peridomestic dependencies, for a total of $30 \mathrm{~min}$ per man. If no bugs were found after this time, a dislodging agent $(0.2 \%$ neopynamin) was sprayed into cracks and 
roof space in order to flush out any possible residual bugs. At the same time, householders were asked about the presence of bugs, plastic bags were checked to see if they had collected any bugs, and paper sheets were checked for fresh bug faeces.

Wall bioassays of insecticidal activity were also carried out in five houses in each of the two communities. The technique was to attach an open sided box to the wall, using nails and adhesive tape, in such a way that the open side was against the treated wall surface. Each box, made from used $X$-ray film, was approximately $12 \times 14 \mathrm{~cm}$, angled to be $4.5 \mathrm{~cm}$ deep at the top but flush at the bottom. The upper edge of the box was prised open before sealing, in order to introduce 10 laboratory reared 5 th instar nymphs of $T$. infestans for the bioassay. Three of such boxes were used in each of five houses in each of the two communities. Bugs were exposed for $24 \mathrm{hr}$ and then transferred to clean containers. Readings of bug knockdown (bugs alive but unable to walk normally) and mortality (bugs unable to cling to inclined papers) were taken at $24 \mathrm{hr}, 7$ days and 14 days. Successive bioassays were carried out at 1, 3, 6, 9 and 12 months after spraying, always fixing the boxes to different positions on the same walls of each of the test houses.

All evaluations were checked by the project supervisors, and an independent evaluation was carried out at 9 and 12 months by an external conultant.

\section{RESULTS}

Applied spray doses - Analysis of four filter papers from each of five test houses was carried out by standard HPLC assay. The assays (Table II) indicate a mean applied dose of $28.5 \mathrm{mg} \mathrm{a.i.} / \mathrm{m}^{2}$ (range 0-59.6) with a tendency for greater variation in applied dose at higher levels of the wall (Fig. 3).

Infestation rates - Prespray evaluation by manual sampling revealed heavy infestations of $T$. infestans in 48 houses in San Jose $(76 \%$ of those evaluated) and in 29 houses in Entre Rios (71\%), with bugs being found in the houses themselves and in associated peridomestic dependencies. Immediately after spraying, householders reported finding large numbers of dead and moribund $T$. infestans which they collected in plastic bags. The total of bugs collected by householders into the plastic bags then declined from 4,392 to 26 in the six months following spraying (Table III) although since these bugs were all dead this result can only be interpreted as a reflection of the initial high densities of bugs in the houses.

The paper sheets in 11 houses revealed 6 of them to have been infested prior to spraying. Of these, manual sampling had revealed infestation
TABLE II

Analysis of deltamethrin deposits on filter papers following house spraying

\begin{tabular}{cccc}
\hline $\begin{array}{c}\text { House } \\
\text { number }\end{array}$ & $\begin{array}{c}\text { Position of filter } \\
\text { paper }(\mathrm{m} \text { above floor })\end{array}$ & $\begin{array}{c}\text { Deltamenthrin } \\
\left(\mathrm{mg} \text { a.i. } / \mathrm{m}^{2}\right)\end{array}$ & Mean \\
\hline 5 & 0.8 & 39.9 & \\
& 1.7 & 37.4 & \\
& 2.05 & 26.4 & 40.8 \\
27 & 2.15 & 59.6 & \\
& 0.5 & 34.7 & \\
& 0.9 & 23.9 & \\
34 & 2.15 & 26.1 & 30.0 \\
& 2.15 & 35.6 & \\
& 0.7 & 30.6 & \\
50 & 1.1 & 19.1 & \\
& 1.75 & 30.3 & \\
& 2.0 & 21.3 & 25.3 \\
53 & 0.9 & 27.7 & \\
& 1.1 & 21.2 & \\
& 1.75 & 20.6 & \\
& 1.8 & 32.1 & 25.4 \\
& 0.3 & 25.7 & \\
& 1.5 & 0 & \\
& 1.65 & 41.2 & \\
& 2.15 & 17.0 & 20.9 \\
\hline
\end{tabular}

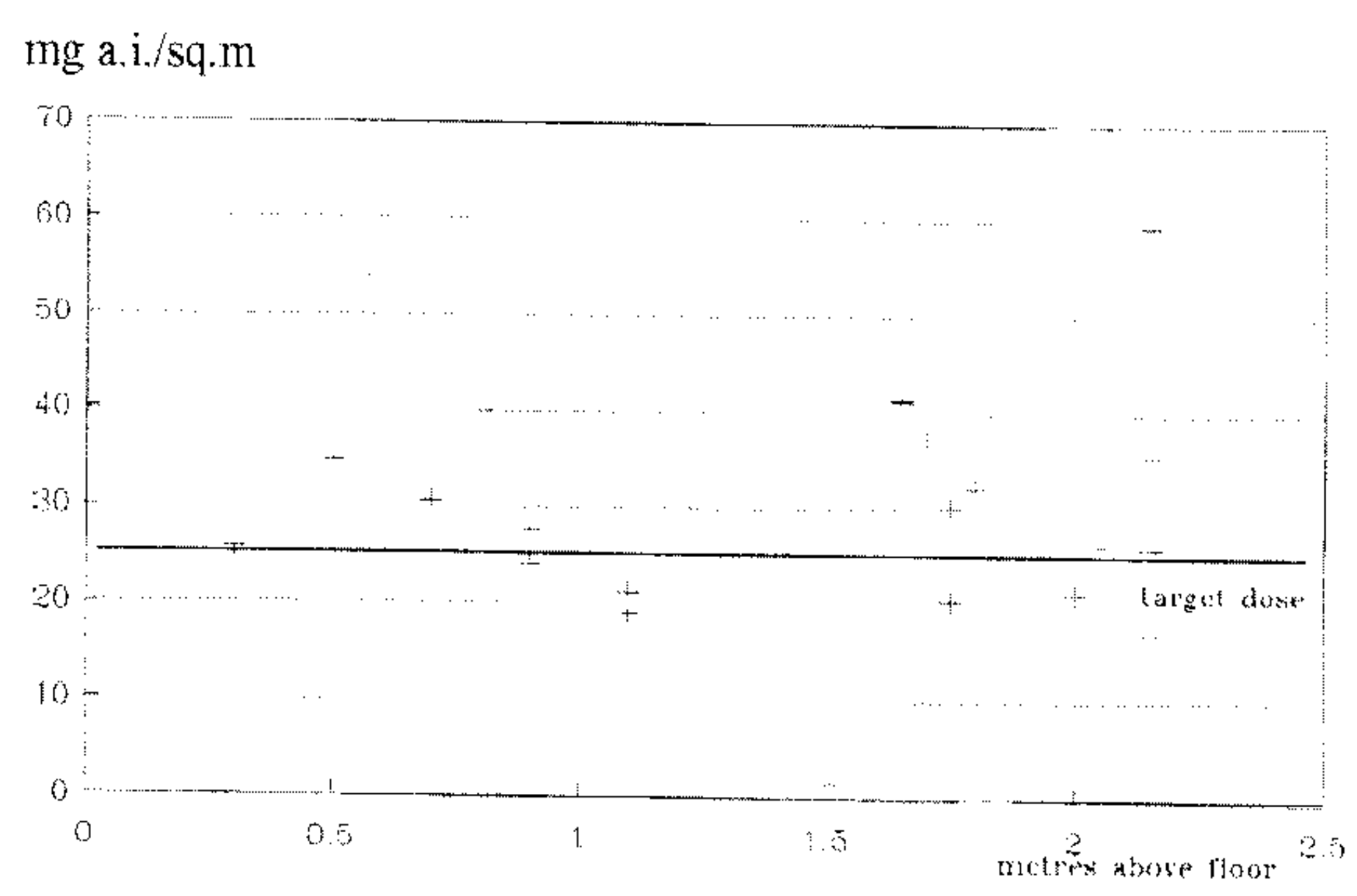

Fig. 3: distribution of applied doses of deltamethrin ( $\mathrm{mg}$ a.i./ $\mathrm{m}^{2}$ ) on filter papers pinned at various heights on house walls, as determined by subsequent HPLC analysis.

\section{TABLE III}

Number of Triatoma infestans collected into plastic bags by householders following deltamethrin spray

\begin{tabular}{lccrcr}
\hline \multirow{2}{*}{ Time after } & \multicolumn{2}{c}{ San Jose } & & \multicolumn{2}{c}{ Entre Rios } \\
\cline { 2 - 3 } \cline { 5 - 6 } spraying & No. houses & No. bugs & & No. houses & No. bugs \\
\hline 2 days & nr & 3224 & & nr & 1168 \\
1 month & 24 & 1284 & & 25 & 254 \\
3 months & 14 & 181 & & 11 & 84 \\
6 months & 4 & 11 & & 2 & 15 \\
9 months & 1 & 2 & & 0 & 0 \\
12 months & 0 & 0 & & 0 & 0
\end{tabular}

nr: not recorded 
only in two of the houses (including one that was negative by paper sheets). This shows the sensitivity of the paper sheet method, and indicates that initial infestation rates were in fact higher than indicated by prespray manual sampling. However, subsequent examination of the paper sheets revealed no new faecal streaks after the spraying, suggesting that live bugs were either absent or unable to obtain bloodmeals.

Manual capture reports indicated $14 \%$ and $17 \%$ residual infestations in houses after 1 month, in San Jose and Entre Rios, respectively. In contrast, no bugs were found by manual sampling from any of the houses at the 3 or 6 month evaluations. At the 9 month evaluation, a single live adult $T$ ] infestans was found in one house in Entre Rios, and the same house was also positive at the 12 months evaluation when bugs (three adults, two 4th instars and one 3rd instar) were also found in peridomestic habitats of two other houses in En-l tre Rios and three in San Jose (Table IV, Fig. 4).

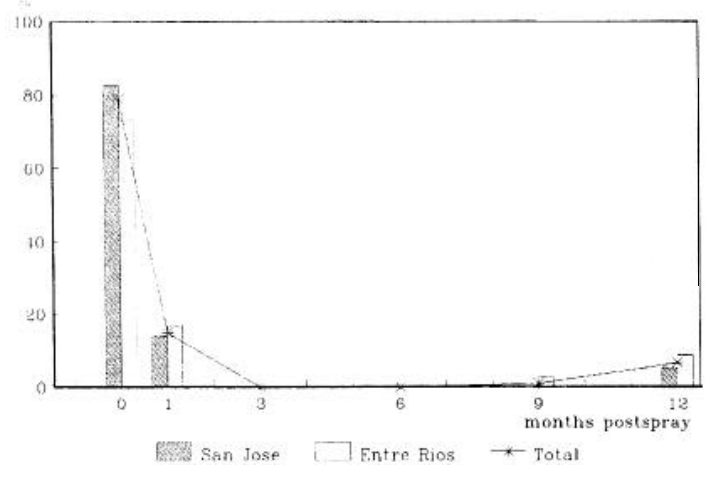

Fig 4: house infestation rates for Triatomdinfestans in San Jose and Entre Rios, before control intervention (month 0) and at successiverevaluations. Prespray infestationl rates are the sum of houses shown positive by manual sampling or by paper sheets to collect fresh bug faeces. However, paper sheets were negative on all subsequent evaluations.
Wall bioassays - Wall bioassays were carried out in five houses of each of the two communities at 1, 3, 6, 9 and 12 months postspray. The results (Fig. 5) show significant residual mortality after 1 month declining to zero at 6 months postspray, but then rising again for the 9 and 12 month evaluations. Knockdown was apparent, especially on shaded interior walls, throughout the evaluation period. Control mortalities were zero in each evaluation.

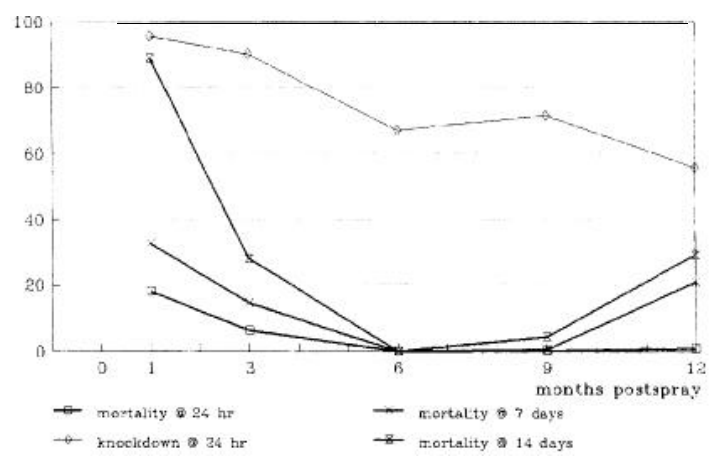

Fig. 5: wall bioassays of knockdown at $24 \mathrm{hr}$, and mortality at $24 \mathrm{hr}, 7$ days and 14 days, following $24 \mathrm{hr}$ exposure of fifth instar Triatoma infestans to house walls sprayed with deltamethrin.

\section{DISCUSSION}

Because of its importance as the primary vector of Chagas disease, elimination of domestic $T$ ] infestans has been given high priority by the southem cone countries of Latin America (Argentina, Bolivia, Brazil, Chile, Paraguay and Uruguay) (PAHO 1993). The results presented here amply demonstrate the effectiveness of the vector control methods applied, and accord with similar experience with deltamethrin and similar pyrethroids in other countries (Pinchin et al. 1980, Diotaiuti \&l Texeira Pinto 1991). Most houses sprayed with

TABLE IV

Number of houses positive for Triatoma infestans, as evaluated by field teams

\begin{tabular}{lcccccc}
\hline & \multicolumn{3}{c}{ San Jose } & \multicolumn{3}{c}{ Entre Rios } \\
\cline { 2 - 7 } & $\begin{array}{c}\text { Houses } \\
\text { evaluated }\end{array}$ & $\begin{array}{c}\text { Houses } \\
\text { positive }\end{array}$ & $\begin{array}{c}\text { \%ouses } \\
\text { evaluated }\end{array}$ & $\begin{array}{c}\text { Houses } \\
\text { positive }\end{array}$ & $\%$ \\
\hline June 1994 (prespray) & 63 & 48 & 76 & 41 & 29 & 71 \\
July 1994 (1 month postspray) & 59 & 8 & 14 & 35 & 6 & 17 \\
Sep. 1994 (3 months postspray) & 47 & 0 & 0 & 33 & 0 & 0 \\
Dec. 1994 (6 months postspray) & 58 & 0 & 0 & 36 & 0 & 0 \\
Mar. 1995 (9 months postspray) & 54 & 0 & 0 & 34 & 1 & 3 \\
June 1995 (12 months postspray) & 56 & 3 & 5 & 34 & 3 & 9 \\
\hline
\end{tabular}


deltamethrin remained free of detectable infestations for more than 12 months. However, even the low levels of reinfestation detected at this time point to the need for continual vigilance and selective retreatment where necessary.

The priority accorded to Chagas disease vector control is amply justified by the medical and economic impact of the disease (World Bank 1993, Del Rey et al. 1995) and by the calculated nett benefits accruing to any investment in vector elimination (Schofield \& Dias 1991). But the social benefits are also tangible, as shown by interviews with householders in the two villages studied here. Prior to the control interventions, house infestation rates had been so high that many people had been obliged to sleep outside their houses because of the biting nuisance. Irrespective of the disease risk therefore, householders manifested extreme gratitude for the control interventions, which allowed them to make full use of their houses without the annoyance of bug infestations. Householders also appreciated the elimination - at least for the summer months - of other domestic insect pests, especially houseflies and fleas.

The initial intervention for this trial was carried out in June 1994, one of the coldest of the winter months when T. infestans populations are at their most vulnerable (Gorla 1988). At this time, the deltamethrin was highly active and remained so until July when its insecticidal activity (as measured by wall bioassays) began to decline. Of particular interest however, is that whereas knockdown activity declined consistently but gently during the 12 month course of the trial, insecticidal activity declined very markedly with the onset of summer only to rise again during the following winter (Fig. 5). This kind of inverse temperature dependence has been noted for other pyrethroids (and is wellknown for DDT) although it seems to vary both with the pyrethroid and with the insect species, and not all combinations show negative temperature dependence as seen here (Miller \& Salgado 1985). Nevertheless, we feel that temperature dependence is an important, but often overlooked, factor in assessing different products for their activity against Triatominae.

Since earliest trials of organochlorine insecticides against domestic Triatominae (Dias \& Pellegrino 1948, Romaiia \& Abalos 1948) it has been assumed that highly residual formulations were required (Pinchin|\&| Schofield 1979). Indeed, much effort has been expended to develop residual formulations, for example using slow-release latex or PVA matrices (Oliveira Filho 1988). However, while it is clear that previously-used organochlorine insecticides such as BHC or dieldrin had greater stability and more prolonged residual action, it is also becoming clear that pyrethroids such as deltamethrin are much more effective in eliminating domestic populations of Triatominae. In the results presented here, for example, all but one of the houses remained free of detectable infestations for 12 months, even though the superficial lethality of the product (as revealed by wall bioassay) had declined to low levels after 3 months. It may be, therefore, that the effectiveness of modem pyrethroids such as deltamethrin rest more with their initial impact in quickly eliminating domestic infestations, rather than in any longer term effect designed to inhibit reinfestations (after all, residual activity becomes irrelevant if there are no bugs left to kill). This in turn would imply that the most effective control strategy would involve wide geographic coverage in order to eliminate possible sources of reinfestant bugs, rather than repeated spraying to eliminate reinfestations.

For the trial reported here, we are unable to assess with certainty the source of the reinfestations. Neighbouring communities - of which the nearest was about $5 \mathrm{~km}$ away, on the other side of the Rio San Juan del Oro - had been sprayed previously and were being periodically evaluated, making them unlikely sources for the reinfestations in Entre Rios and San Jose. In Entre Rios, the single house where reinfestant bugs were found at the 9 and 12 month evaluations, was the most distant from other occupied houses (about $500 \mathrm{~m}$ away). It had a single male occupant who travelled frequently to other parts of Bolivia in search of temporary work, which may suggest that the reinfestant bugs had been carried by him from another region. However, this house was close to three abandoned houses which had been sprayed only about their external walls, and which may have housed some bugs untouched by the intervention. Similarly, we assume that the bugs found at the 12 month evaluation in three chicken houses and two goat stables in Entre Rios and San Jose may also have come from abandoned houses that had been sprayed only over their outside walls. At present, we discount the possibility of reinvasion from a silvatic population because no such foci have been reported for the Tupiza region (Dujardin et al. 1996) and we did not find evidence of silvatic bugs during examination of rockpiles and cactus stands where wild rodents had been seen. Moreover, on morphometric evidence the reinfestant adult bugs complied with the known patterns of domestic bugs rather than with those of silvatic bugs from elsewhere in Bolivia (JP Dujardin, pers. comm.).

In the trial reported here, the control strategy involved insecticide spraying alone, and the two communities ( 241 houses in total) were treated by the five two-man teams within five days (approxi- 
mately| ten houses per day per team). Elsewhere in the project area however, the control strategy also included elements of house improvement as a prerequisite for spraying. This strategy was in response to the policies of the World Food Programme (WFP) which supported the Chagas control activities mainly through donations of food aid given to householders as incentive to carry out the house improvement work. Estimates carried out elsewhere in the P Cotagaita area indicate that house improvement plus spraying required approximately ten man days per house (excluding the work of the householders themselves) at an average cost per house of 475 pesos bolivianos (approx. US\$ 100), compared to less than a quarter man-day per house for insecticide treatment alone at an average cost of 235 pesos bolivianos per house (approx. US\$49| per house) (Table V).

\section{TABLE V}

Proyecto Cotagaita San Juan del Oro: estimated average costs per house treated ${ }^{q}$

\begin{tabular}{lr}
\hline & $\begin{array}{r}\text { Bolivian } \\
\text { pesos }^{b}\end{array}$ \\
\hline Insecticide & 168.00 \\
Operational costs (transport, per diems, etc.) & 67.00 \\
Value of WFP Food Aid & 120.00 \\
Local labour and mterials for & \\
house Improvement & 120.00 \\
\hline Total & 475.00
\end{tabular}

a: source - P Cotagaita (1994); $b$ : US $\$ \mathbf{1} .00=$ approximately 4.76 Bolivian pesos

Clearly, improved housing is a valid objective, especially for poorer rural areas. But to include this as a prerequisite for vector control brings few advantages. There may be a marginal improvement to insecticide performance on improved less porous wall surfaces, and in some cases the improvements may restrict the number of resting places for the triatomine bugs (Schofield \& Marsdenl 1980). However the disadvantages are substantial. Firstly, the improvements themselves do not and cannot eliminate domestic bug populations, since they cannot be carried out to a sufficiently high standard because of the cost implications, but nevertheless the improvements do represent a major cost in time as well as direct economic terms, leading to much slower implementation of direct action against the vectors. Most importantly, there will always be, in any poor community, families who enter without the possibility to build a high quality house, so that programmes of house improvement can never keep pace with the creation of new domestic sites at risk to bug infestation. In contrast, insecticide application without the constraint of concurrent house improvement work - can be rapid, effective, and can keep pace with erection of new buildings. Then, once domestic bug populations have been eliminated from within a community, house improvement programmes can proceed at their own pace, with no risk of reinfestation provided sufficient geographic coverage has been achieved by the insecticide programme to eliminate potential foci of reinfestant bugs.

The work of the P Cotagaita has amply illustrated this conclusion. The area of trial (San Juan and Entre Rios) had not been subject to house improvement, and yet bugs appear to have been virtually eliminated, and the cost was much lower than that of other areas where house improvement was been included in the control strategy. It must therefore be recommended that the methodology adopted by the trial be adopted as the primary approach to large scale elimination of T.infestans, and that such a programme be divorced from parallel programmes of house improvement.

\section{ACKNOWLEDGEMENTS}

To the authorities and villagers of San Jose de la Pampa Grande and Entre Rios de Ajnapa for their assistance and support for this work. To all those involved in the control interventions and evaluations, especially Jose Luis Chambi, Raul Prieto, Octavio Colque, Alberto Leon, Francisco Solozano, Simon Flores, Willi Flores and Roberto Lopez. Analysis of spray deposits was carried out at Agrevo Environmental Health, Berkhamsted, UK.

\section{REFERENCES}

Dias E, Pellegrino J 1948. Alguns ensaios corn o "gammexane" no combatel aos transmissores da doença de Chagas. Brasil Medico 62: 185† 191.

Del Rey EC, Basombrio MA, Rojas CL 1995. Beneficios brutos de la prevencion del mall de Chagas. Castanares (cuadernos dell IIEX 4: I-75.

Diotaiuti L, Texeira Pinto C 1991. Susceptibilidade biológical do Triatoma sordidd e Triatoma infestans a deltametrina e lambdacyhalotrina em condiçōes de campo.] Rev Sod Bras Med Trop 24: 15 1-155.

Dujardin JP, Schofield CJ, Tibayrenc M 1997. Population structure of Andean Triatoma infestans: an isozymic study and its epidemiological relevance. Med Vet Entomol (in press).

Garcia Zapata MT, Schofield CJ, Marsdenl PD 1985. A simple method for detecting the presence of live triatomine bugs in houses sprayed with insecticides. Trans $R$ Sod Trop Med Hyg 79: 558-559.

Gorla DE 1988. Seasonal effects on control strategies of Chagas disease vectors. Rev Arg Microbiol 20 (supl): 71-80.

Miller TA, Salgado VL 1985. The mode of action of pyrethroids on insects, p. 43-77. In JP Leaheyl The Pyrethroid Insecticides, Taylor \& Francis, London. 
Oliveira Filho AM 1988. Development of insecticide formulations and determination of dosages and application schedules to fit specific situations. Rev Arg

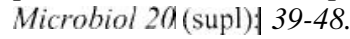

PAHOl 1984. Status of Chagas disease in the region of the Americas. PAHO Epidenziol Bull 5: 5-9

PAHO 1993. Iniciativa del Cono SurJPAHOl document no. PNSP/92-18」 rev. 1. Pan American Health Organization, Washington DC, $36 \mathrm{pp}$.

Pinchinl R, Oliveira Filho AM de, Fanara DM, Gilbert B 1980J Ensaio de campo para avaliaçào das possibilidades de uso da decametrina (OMS 1998) no combatel a triatomineos. Rev Bras Malariol Doenças Trop 32: 36-41

Pinchin R, Schofield CJ 1979. The design of insecticides for the control of domestic vectors of Chagas disease. II Congresso International sobre a Doençal de Chagas, Rio de Janeiro, Brazil.

P Cotagaita 1994. Ejecucidn de Proyectos de Desarrollo Rural. Proyecto Cotagaita San Juan del Oro, Tupiza. $439 \mathrm{pp}$.

Romanal C, Abalos JW 1948. Accionl del Gamexane sobre los triatomideos. Control domiciliario. Anales Inst Med Reg Tucumand 2: 95-106]
Schofield CJ, Dias JCP 1991. A cost-benefit analysis of Chagas disease control. Mem Inst OswaldolCrual 86: 285-295.

Schofield CJ, Marsdenl PD 1980. The effect of wall plaster on a domestic population of Triatoma infestans: WHO/VBC/80.757! World Health Organization! Geneva.

Schofield CJ, Williams NG, Kirkl ML, Garcia Zapata MT, Marsden PD 1986. A key for tdentifymg faecal smears to detect domestic infestations of triatomıne bugs. Rev Soc Bras Med Trop 19: 5-8.

SNSl 1994. Programd Nacional de Control de Chagas. Bolivia」 Ministerio de Desarrollo Humano, Secretaria Nacional de Salud, La Paz, 29 pp.

SNS/CCH 1994. Chagas Disease in Bolivia」CCHUSAIDI La Paz, 93 pp.

Valencia A 1990. Investigación|Epidemiologica| Nacional de la Enfermedad de Chagas. Ministerio de Previson Social y Salud Publical La Paz, 184 pp.

WHO 1992. Control of Chagas Disease 1 Technical Report Series 811. WHO Geneva, 95 pp.

World Bank 1993. World Development Report 1993. Investing in Health. Oxford University Press, New York, 329 pp. 